\title{
Healing the Fundamental Unit of Heredity (Gene Therapy): Current Perspective and What the Future Holds
}

\author{
Bunga Anggreini Sari ${ }^{1}$, Azalia Talitha Zahra1 ${ }^{1}$, Ganda Purba Tasti ${ }^{1}$, Ziske Maritska² \\ ${ }^{1}$ Master of Biomedical Science, Faculty of Medicine, Sriwijaya University, Palembang, Indonesia \\ ${ }^{2}$ Department of Biology Medicine, Faculty of Medicine, Sriwijaya University, Palembang, Indonesia
}

\begin{abstract}
The ability to make precise adjustments to the human genome has been a goal of healing in which gene also introduces as the fundamental unit of heredity, in biomolecular technology in genetic diseases have opened new knowledge such as gene therapy. Gene therapy is a technique to repair DNA where its usage is to treat the malignancy and inherited genetic diseases. Gene therapy is a choice to the genetic cloth that goals to remedy a sickness this is hard to deal with or perhaps has no treatment. Currently, gene remedy is done in approaches to patients, specifically embryonic cells and somatic cells, every in vivo and ex vivo. Moral considerations with modification of the difficulty's cells and oversight of regulation and reagents want to be taken into consideration within the gene therapy project. Applications for using gene remedies have begun to be widely used, which include in case of maximum cancers, coronary heart disorder, infectious sicknesses, and others. Gene therapy has spread to a wide range of applications then go beyond the modification of genetic disorders. Advances in genetic modification of cancer cells and immunity and the use of viruses and bacteria to control cancer cells have resulted in many clinical trials and product developments for cancer treatment. The miracles and blessings of gene therapy are might believe, but even though they are being studied and developed now and, in the future, so that the desire for gene therapy may be even better future.
\end{abstract}

Keywords: gene therapy, genetic recombination, gene therapy application

\section{Introduction}

Many experts believe that gene therapy is the way to shift medicine away from a chronic disease management approach toward disease interception and prevention. Genetics constantly has a role to every disease. DNA variants and the differential work of DNA and the environment in which humans develop have a big share in every disease.
As understood with the help of genetic repair capabilities through gene correction or specific modification areas for the selected treatment target, gene treatment is a disease healing technique or therapy by shifting one or more nucleic acids to target cells using the repair of the defective gene. ${ }^{1,2,3}$

Gene therapy is a laboratory experiment that includes a group of drugs for advanced therapy, and also modified cells and tissues in which gene therapy technology never

Date of submission: February 27, 2021

Last Revised: May 4, 2021

Accepted for publication: May 11, 2021

Corresponding Author:

Ziske Maritska

Department of Biology Medicine

Faculty of Medicine, Sriwijaya University

Jl. Dokter Muhammad Ali, Sekip Jaya, Palembang, Indonesia

e-mail: ziske_maritska@unsri.ac.id

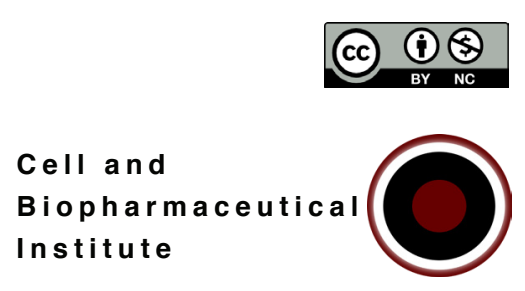


breaks from genetic manipulation in terms of producing a Genetically Modified Organism (GMO). The way gene therapy works is by repairing and deactivating or replacing malfunctioning genes that can cause disease in order to rebuild normal function. Therefore, gene therapy has the potential to cure diseases that cannot be cured with natural therapy and cure incurable diseases. Gene therapy treatments have great potential in genetic diseases such as cancer, specific viral infections, and recessive genetic disorders (cystic fibrosis, hemophilia, muscular dystrophy, and sickle cell anemia)., ${ }^{1,-6}$

Currently, there are about 2,000 clinical trials of gene therapy in various diseases that have occurred or are in progress. ${ }^{3}$ Several clinical trials in 2018 regarding gene therapy in $\beta$-thalassemia patients using transfusions stated that therapy of $\mathrm{CD} 34^{+}$cells transduced in the BB305 vector could reduce or even eliminate the need for red blood cell transfusions in 22 patients with severe $\beta$-thalassemia without any side effects. ${ }^{6}$ Whereas in another study in 2017 stated that a single infusion of SPK-9001 could consistently increase the activation of coagulant factor IX by $30 \%$, which allowed discontinuation of prophylaxis, bleeding and eliminated exogenous needs in 3 men with hemophilia B. In children with associated hemophilia $\mathrm{B}$, hypophosphatemia-X treatment with burosumab can increase phosphate reabsorption in the renal tubules, serum phosphorus levels, physical function, and reduce the pain and severity of rickets. ${ }^{7}$ In some cases, gene therapy can stop disease progression completely by addressing and correcting the underlying genetic causes, decreasing its morbidity, and increasing its survival. 8

Based on the success of several studies above, gene therapy is known as one of the efforts in scientific breakthroughs. Various methodologies in genetic engineering for advances in the development of gene therapy vector systems are being optimized for gene transfer. This is a new and unique approach to treating previously difficult-to-treat diseases using gene therapy. Gene therapy addresses the root causes of genetic diseases by modifying the patient's gene expression or by repairing or replacing abnormal genes, rather than treating the symptoms of the disease. However, this gene therapy process remains complex and there are still many techniques that require new developments. Therefore, in this article, the author discussed gene therapy, its history, the methods that have been developed, its current application, and the prospects for gene therapy in the future.

\section{How It All Starts and How Things Stands}

Gene therapy was first recognized in the 1980s because they used genetic theory. ${ }^{1}$ The National Institutes of Health (NIH) and The Food and Drug Administration (FDA) have played an important role in the emergence of safe and effective human gene therapy. The first breakthrough to be made was recombinant DNA technology. ${ }^{9}$ The first experiment was issued at the National Institutes of Health in 1989 regarding tumor infiltration using a retroviral vector that was reinfused to examine the capacity of tumor cells. The result of the experiment showed human cells could be genetically modified and returned to the harmless patient. From this research, new experiments have sprung up around the world until now. ${ }^{10}$

Efforts are being made to improve the understanding of the biological basis of diseases such as transmission of genes, potential adverse events encountered. In addition, scientific advances can also increase awareness of safety, efficiency, and transmission of gene transfer. There are three conceptual techniques in gene therapy, including: 1) DNA recombination technology, which works when a healthy gene or desired gene is assigned to a vector as plasmid or viral nanostructures; 2) treatment with synthetic oligonucleotides which contain several blocks of the genome structure called nucleotides; and 3) Delivery of messenger Ribonucleic acid (mRNA). ${ }^{9}$

Currently, there have been countless successful experiments and thousands of studies such as gene delivery technology, target cell biology, gene therapy and understanding target diseases. However, there are always complex attempts at development in technical gene therapy, this could be a serious problem for now and even in the future. ${ }^{11}$ It is currently reported that the use of an oligonucleotide-induced exon skipping form for the treatment of Duchenne muscular dystrophy (DMD) and spinal muscular atrophy (SMA) explains a promising outcome approach is inefficient for gene therapy in humans. ${ }^{1,11,12}$

\section{Gene Therapy Classification}

There are two types of gene therapy based on the origin of the cells, namely embryonal cell (germline gene therapy) and somatic cell (somatic gene therapy). ${ }^{1}$ Each of them will be explained in the next sub-section. 


\section{Germline Gene Therapy}

Germline gene therapy is gene therapy with modified sperm or egg cells with some genome replacement function. This modification will be passed from generation to generation to all subsequent generations. In other words, this gene therapy should be a very effective management to prevent genetic diseases. However, despite its potential to prevent congenital disease, germline therapy is highly controversial and there has been little research in its field for technical or ethical reasons. ${ }^{1,13-15}$

In germline gene therapy, stem cells such as sperm and eggs are modified by inserting updated genes into the genome. Modifications in this way can be made from generation to generation to create the next generation. This is why germline gene therapy is very effective in correcting genetic diseases. ${ }^{1}$

Germline gene therapy transfers genes into the ovum or zygote which leads to ovum fertilization of ovum by sperm to form a zygote and by carrying the previously inserted zygote, genes will be developed and the formed new organism has genes that function in the intended therapy. ${ }^{14}$

\section{Somatic Gene Therapy}

Somatic Gene Therapy works when the therapeutic gene has been transferred to the patient's somatic cells. Functional DNA is transferred to target cells via in vivo or ex vivo. In this gene therapy, the target cells will not be able to pass generations. These genes are transferred directly to the targeted organs in order to be functionable as desired. Somatic Gene Therapy will not affect embryonic cells. This gene therapy is provided as the premier genetic laboratory worldwide. ${ }^{1,6}$

Somatic cell gene therapy is a technology with a wide range of applications used in human health. One example of somatic cell gene therapy is DNA vaccination, which is a procedure similar to conventional vaccination. In this therapy, any side effects are limited to these patients and are not passed on to the next generation. ${ }^{13}$ In general, the individual genetic makeup is not affected by the corrected changes, but this therapy can be repaired and contribute to the normal function of the damaged organ. ${ }^{16}$

Somatic cell gene therapy is considered the only therapy that can be accepted by society, this is because this therapy can affect cells, tissues, or organs that are targeted by sufferers and are not passed on to the next generation. This therapy is a genome modification exemplified by Clustered technology, Regularly Interspaced, Short Palindromic
Repeats (CRISPR) or epigenetic modification with a gene therapy approach with the same effect. This somatic cell gene therapy has two categories, namely ex vivo and in vivo. ${ }^{17}$

\section{Gene Transfer Methods}

Gene transfer is performed by using transfection techniques to transfer nucleic acids which include non-viral methods, physical methods and chemical methods.

\section{Non-Viral Method}

Non-viral vectors usually known as naked DNA are easier to produce in large numbers and have less immune response from the host. In the last decade, low transfection rates and low gene expression have been identified as drawbacks of this method. However, recent advances in vector technology have resulted in molecular production and engineering with the same efficiency as viral engineering. Transfection is a method for overcoming the problem of insertion of negatively charged molecules (DNA and RNA phosphate skeletons) into cells with negatively charged membranes. Normal use (modified organic silica or silicates) is another non-viral method. This ease of work makes silica a good choice for gene delivery. ${ }^{18,19}$

Injection of naked DNA is a method of non-viral transfer its simplest. This method is performed with naked plasmid PCR. However, the cell retrieval of DNA naked is generally inefficient. Naked DNA injection focuses on increasing the efficiency of DNA retrieval by developing new methods such as; electroporation, sonoporation, and use of genes, in which DNA coated with gold particles is introduced into cells with helium. ${ }^{18}$

\section{Physical Methods}

In this physical method, DNA delivery uses small injections into embryonic stem cells to produce transgenic organisms in addition to transferring antisense RNA to Caenorhabditis elegans. Electrophoresis is an impulse high-voltage method for transferring DNA from cell membranes. On the surface of the cell membrane, small pores are formed temporarily as a result of electric shock. This electrophoresis can be applied to various types of cells, the high rate of cell death can limit its use in clinical applications..$^{18,19}$

Another physical method for gene transfer is biolistic particle delivery, also known as a particle bomber. This method relies on high-speed micro-processing of nucleic 
acids into the receiving cell using membrane penetration. This method has been used successfully in the delivery of nucleic acids to cultured cells and cells in vivo. ${ }^{19}$

\section{Chemical Methods}

Gene therapy used synthetic oligonucleotides to deactivate genes involved in the disease process. By using the specific antisense for the target gene will crate impairment of the transcription of the defective gene. Dendrimers are branched macromolecules whose particle surfaces can be filled by various methods, and many of the final structural properties of the particles are determined by these surfaces. The presence of genetic material such as DNA or RNA results in temporary nucleic acid linkages with cationic dendrimers. ${ }^{18}$

\section{Challenges in Gene Therapy}

The capacity of gene therapy to cure human diseases is currently a good reality, the need for surveillance, ethical considerations related to the genetic modification of the subject's cells, and the availability of suitable skills, infrastructure and reagents are also materials that should be considered very carefully. ${ }^{10,11}$ Recently there has been a debate about genetic ethics between the Japanese, British and American ethical committees where experiments on healthy human embryos have been approved by the Japanese and British ethical committees, but in America it is still conservative which states that the experiment is still waiting for improvements in the use of the technique and ethical issues. ${ }^{1}$

\section{Gene Therapy Applications}

Gene therapy can be used as an alternative treatment for diseases for which no cure or vaccine has yet been found. There are several criteria for selecting gene therapy diseases in humans ${ }^{14}$, namely: 1) An incurable disease; 2) The affected organs, tissues, and cell types have been identified; 3) The defective normal gene has been isolated and cloned; 4) Introduction of normal genes into the target tissue; and 5) Genes can be expressed adequately techniques are available to verify the safety of the procedure.

Cancer, cardiovascular disease, infectious diseases, monogenic diseases, vision-related diseases, neurological diseases, and so on are assumed to be curable with gene therapy. The disease can be treated if the associated gene is identified and its functional gene is found that can substitute the abnormal gene. All of these decades there's about 1437 trials, currently, clinical trials of gene therapy in treating cancer $(65.0 \%)$ and monogenic diseases $(11.1 \%)$ have achieved great success in current gene therapy, namely $76.1 \%$. Although trials targeting cardiovascular disease outnumber trials for the monogenic disease since 2004, this trial is now the fourth most common indication $(6.9 \%)$ as a result of an increasing number of trials targeting infectious diseases $(7.0 \%) .6 .11$

Adeno-Associated Virus (AAV) vectors can deliver tumor-specific antigens to generate humoral and T-cell responses. Approaches have been explored in preclinical models of murine and non-human primates that have potential vectors for conditions such as cervical cancer, and prostate cancer. In addition, uncoded nucleic acid delivery such as microRNA is effective in promoting cardiac regeneration, thus exhibiting curative properties that have so far only been present in stem cells. ${ }^{20}$ In Sickle Cell Disease (SCD) it is not known that trials show that high anti-sickle $\beta$-globin expression can reverse disease complications. ${ }^{21}$ Genetic approaches can be adapted and standardized with high efficiency, such as increasing the level of $\mathrm{HbF}$ protein in the blood of SCD patients by adding or controlling the suppressor $\gamma$-globin gene. Activator via gene editing will also be an additional option providing preclinical results. Further clinical trials are expected in the future. ${ }^{22}$

\section{Benefits of Gene Therapy}

Gene therapy has many benefits, including: 1) gene silencing, where individual cases of HIV infection can be suppressed with gene therapy to protect patients from pain and suffering before the disease progresses; 2) Gene therapy has the potential to eliminate and prevent hereditary diseases such as cystic fibrosis; 3 ) create a new field of medicine based on technology; and 4) Regulatory approval for gene therapy licensing is increasing. ${ }^{18,23}$ A major advantage of gene therapy is that continuing expression of the gene(s) allows for a cure following single treatment as opposed to continuous administration of a drug with a relatively short half-life. ${ }^{24}$

\section{Disadvantages of Gene Therapy}

Although gene therapy has the potential to prevent morbidity for years with one treatment, this gene therapy has a very expensive cost..$^{25}$ The renewal of gene therapy methods is 
one of its drawbacks. Stimulation of the immune response in which genes are injected by the virus in the body can cause an immune response and pathogenic viral vectors. Besides, the generation of genetic disorders due to the presence of multigene which are the genetic material being transferred does not necessarily enter the target cells, even if they do, it may not be placed in the right place in the genome. ${ }^{18}$

\section{What the Future Holds}

Gene therapy knowledge is considered an important new approach compared to conventional medicine. This raises a lot of hope for the future regarding gene therapy. Gene therapy facilitates the continuous, stable, and regular expression of biological agents by targeted delivery of genes containing genetic information. ${ }^{18,26}$

Gene therapy using the cell division potential and transplantation of the immunity cell to removing the targeted cell in a certain case. Another important challenge is before the effect that should be handled before the therapeutic approach has been fully aware. As the number of reported successes of gene therapy increases, other factors associated with processing need to be considered such as; target disease from gene therapy. Gene therapy also currently offers the potential for a single treatment that produces a lifelong cure, leading to a discussion of how much therapy is valued and how expensive it is. ${ }^{11,18}$

The gene therapy capacity is to cure human disease now an established reality, but for now, many disease phenotypes and the pathophysiological process will create potential to this exciting therapeutic approach which lies beyond the reach of existing technology. Achilles heel of gene therapy was once described as the ability to achieve efficient gene delivery. Even though there are several successful protocols, the process of gene therapy remains complex, and many techniques need new developments. The specific body cells that need treatment should be identified and accessible. The effective way to distribute the gene copies to the cells must be available, and the diseases and their strict genetic bonds need to be completely understood. ${ }^{1,11}$

\section{Conclusion}

The involvement of molecular biology has made it easier for researchers to manipulate genes, one of which is by utilizing the development of gene therapy. Gene therapy is a treatment method by transferring certain functional genes so that they can replace the function of abnormal genes related to the disease. The advantages and disadvantages of gene therapy, challenges in the pros and cons of gene therapy methods certainly exist, however, this is what makes the basis for gene therapy to be better in the future.

\section{References}

1. Gonçalves GAR, Paiva RMA. Gene therapy: advances, challenges and perspectives. Einstein (Sao Paulo). 2017; 15(3): 369-75.

2. Jackson M, Marks L, May GHW, Wilson JB. The genetic basis of disease. Essays Biochem. 2018; 62(5): 643-723.

3. Kumar SR, Markusic DM, Biswas M, High KA, Herzog RW. Clinical development of gene therapy: results and lessons from recent successes. Mol Ther Methods Clin Dev. 2016; 3: 16034. doi: 10.1038/mtm.2016.34

4. Hampson G, Towse A, Pearson SD, Dreitlein WB, Henshall C. Gene therapy: evidence, value and affordability in the US health care system. J Comp Eff Res. 2018; 7(1): 15-28.

5. Smith CIE, Blomberg P. Genterapi - från idé till verklighet - Ännu har få patienter behandlats och preparaten är ofta mycket dyra men utvecklingen går fort nu [Gene therapy - from idea to reality]. Lakartidningen. 2017; 114: EWYL.

6. Thompson AA, Walters MC, Kwiatkowski J, Rasko JEJ, Ribeil JA, Hongeng S, et al. Gene therapy in patients with transfusiondependent $\beta$-thalassemia. N Engl J Med. 2018; 378(16): 1479-93.

7. George LA, Sullivan SK, Giermasz A, Rasko JEJ, Samelson-Jones BJ, Ducore J, et al. Hemophilia B gene therapy with a high-specificactivity factor IX variant. N Engl J Med. 2017; 377: 2215-27.

8 Carpenter TO, Whyte MP, Imel EA, Boot AM, Högler W, Linglart A, et al. Burosumab therapy in children with X-linked hypophosphatemia. N Engl J Med. 2018; 378: 1987-98.

9. Collins FS, Gottlieb S. The next phase of human gene-therapy oversight. N Engl J Med. 2018; 379: 1393-5.

10. Ginn S, Alexander I. 2016. Gene therapy. In: Balakrishnan N, Colton T, Everitt B, Piegorsch W, Ruggeri F, Teugels JL, editor. Wiley StatsRef: Statistics Reference Online. New Jersey: John Wiley \& Sons; 2016. p.1-19.

11. Ginn SL, Amaya AK, Alexander IE, Edelstein M, Abedi MR. Gene therapy clinical trials worldwide to 2017: An update. J Gene Med. 2018; 20: e3015. doi: 10.1002/jgm.3015.

12. Glorioso JC, Lemoine N. Gene therapy-from small beginnings to where we are now. Gene Ther. 2017; 24(9): 495-6.

13. Macpherson I, Roqué MV, Segarra I. Ethical challenges of germline genetic enhancement. Front Genet. 2019; 10: 767. doi: 10.3389/ fgene.2019.00767.

14. Patil S, Al-Zoubi IA, Raghuram PH, Misra N, Yadav N, Alam MK. Gene therapy: A comprehensive review. Int Med J. 2018; 25(6): $361-4$

15. Wolf DP, Mitalipov PA, Mitalipov SM. Principles of and strategies for germline gene therapy. Nat Med. 2019; 25(6): 890-7.

16. Spatz MA. Genetics home reference. J Med Libr Assoc. 2004; 92(2): 282-3

17. Sinha S, Ghosh A, Rao JG, Jotwani G, Kharkwal G, editors. National Guidelines for Gene TherapyProduct Development and Clinical Trials. New Delhi: Indian Council of Medical Research; 2019.

18. Yazdani A, Alirezaie Z, Motamedi M, Amani J. Gene therapy: a new approach in modern medicine. Int J Med Rev. 2018; 5(3): 36-17. 
19. Silvia Hardiany N. Metode transfer asam nukleat sebagai dasar terapi gen. eJKI. 2017; 4(3): 204-10.

20. Santiago-Ortiz JL, Schaffer DV. Adeno-associated virus (AAV) vectors in cancer gene therapy. J Control Release. 2016; 240: 287301.

21. Gabisonia K, Recchia FA. Gene therapy for heart failure: new perspectives. Curr Heart Fail Rep. 2018; 15(6): 340-9.

22. Demirci S, Uchida N, Tisdale JF. Gene therapy for sickle cell disease: An update. Cytotherapy. 2018; 20(7): 899-910
23. Anguela XM, High KA. Entering the modern era of gene therapy. Annu Rev Med. 2019; 70: 273-288.

24. Gyles C. The promise of gene therapy. Can Vet J. 2018; 59(6): 571-4.

25. Salzman R, Cook F, Hunt T, Malech HL, Reilly P, Foss-Campbell B, et al. Addressing the value of gene therapy and enhancing patient access to transformative treatments. Mol Ther. 2018; 26(12): 2717 26.

26. Keeler AM, ElMallah MK, Flotte TR. Gene therapy 2017: progress and future directions. Clin Transl Sci. 2017; 10(4): 242-8. 